\title{
Development of the concept of recurrent metamodeling to create projects of promising designs of mining machines
}

\author{
Kostiantyn Zabolotnyi ${ }^{1 *}$, Oleksandr Zhupiiev ${ }^{1}$, Olena Panchenko ${ }^{1}$, Andrii Tipikin ${ }^{1}$ \\ ${ }^{1}$ Dnipro University of Technology, Department of Mining Machines and Engineering, \\ 19 Yavornytskoho Ave., 49005 Dnipro, Ukraine
}

\begin{abstract}
In the work on the example of a tunnel erector, the concept of recurrent metamodeling is determined which allows engineering new designs of mining machines. In this case, the metamodel of their entire family is associated with the family of models of machine nodes. The effect of various laws of movement of the erector devices is analyzed and it is proved that its minimum time is observed under conditions of compliance with the U-shaped law. A mathematical model of the hydraulic drive of the erector devices has been developed, which allows, taking into account any options for moving the point mass, to determine the law of control of the movement of the spool of the hydraulic directional control valve (DCV) in relation to the laminar and turbulent type of liquid flow. The erector device metamodel was created using the algorithmic language MATLAB Simulink.
\end{abstract}

\section{Introduction}

In the conditions of modern market relations, most of the technical facilities that are produced by domestic enterprises are inferior to their foreign counterparts in quality, reliability, and cost. To improve them, the scientists of our university, on the basis of the development of new methods of mathematical and computer modeling, have developed a whole range of methodical guidelines aimed at choosing the rational parameters of mining and transport vehicles. So, scientists justify the structural and kinematic scheme of continuously variable transmissions [1], offer an innovative approach to the development of hydrostatic-mechanical transmission of a mine diesel locomotive [2]. At the same time, mathematical models of dynamic processes that arise in the engine of a dump truck in extreme conditions have been created for the first time [3]. The parameters of the fixed jaw of the crusher $[4,5]$ are also optimized, and the stress state of the vibratory feeder under shock loads has been studied [6]. The results of scientific research in the field of mechanics of new designs of mine hoisting machines are also of great practical importance. This concerns the justification of new methods for determining the loads during multilayer winding of a rubber cable [7], including assessing the effect of parameters of a rubber cable on the rigidity of the winding body [8]. Other sources are devoted to the theory of laying a

\footnotetext{
${ }^{*}$ Corresponding author: Zabolotnyi.k.s@nmu.one
} 
hoisting rope on a drum $[9,10]$, justification of the algorithm for selecting the parameters of the elastic lining of the drums [11], determination of the dependence of dynamic parameters on the parameters of the technical condition of individual units of the installation $[12,13]$, and may be useful in the practice of studying the stress-strain state of drums of mine hoisting machines [14]. Noteworthy is the work on substantiating the parameters of equipment for dewatering the ropes of mine hoisting plants [15], as well as the study of equipment for the development of gas-bearing coal seams [16]. Works [17, 18] are devoted to the creation and improvement of the energy-mechanical equipment of mining enterprises, and in works $[19,20]$ the problem of introducing heat pump technologies in mining enterprises is solved.

Mathematical models have been developed describing the frictional properties of mechanical systems [21], as well as the influence of thermophysical processes on the frictional properties of mechanical systems [22], with distributed and concentrated parameters in stationary and non-stationary rectilinear motion. The results of the scientific works on the creation of optimization methods for drive parameters of mine locomotives with increased traction and braking properties made it possible to develop new generation mining equipment $[23,24]$.

At the same time, the use of existing techniques does not allow to achieve the necessary results because of the complexity of design objects. The use of optimization methods is considered a modern design approach. For example, the structural optimization considered by scientists [4] theoretically allows to create in an automatic mode a machine that is optimal in structure. And yet, due to the complexity of formalizing the description of this structure, it turned out that it is practically impossible to use the optimization method in the design of mining machines. In this connection, it was proposed to use generalizedparametric modeling of mining machines [9], according to which a simplified model of the object with averaged parameters was built, its optimization was carried out, and then, taking into account the optimal values of the generalized parameters, a constructive decision was made. This approach also has drawbacks, because generalized-parametric models assume to take into account only a quantitative change in the characteristics of the object. Under these conditions, the development of a new method for designing mining machines is an urgent scientific task. The authors propose combining recurrent metamodeling as a part of the system analysis and CASE technologies with generalizedparametric modeling of mining machine designs. In this case, the family of models of nodes and machines that are qualitatively different from each other is associated with the model of the entire family of these objects, the so-called metamodel. Then, after conducting a computational experiment using specific models of this family, a metamodel is recursively modified to give it new qualitative properties, after which parametric optimization is performed with respect to the basic model of the mining machine. Let us demonstrate this by the example of designing a tunnel erector $[25,26]$. This is one of the most complex mining machines, combining interconnected mechanical and hydraulic processes, and for its optimal design it is necessary to use new methods of structural optimization, in particular metamodeling. Using this machine, prefabricated elements of the tunnel lining of underground workings are laid [27]. In the process of driving tunnels of different diameters, the parameters of the erector vary over a very wide range, which requires a large number of time-consuming calculations if traditional design methods are used [28].

\section{Formalization of the metastructure description of the erector device class}

Let us introduce the definition of a class of homogeneous devices having a similar type of drive (hydraulic drive) and mechanisms that, in the first degree of approximation, can be 
considered as having one degree of freedom: either translational or rotational. The tunnel erector belongs to this class (Fig. 1). It consists of the following devices: translational movement of the manipulator 1 , visors, supporting beams 3 , arches 4 , service platforms 5 , a device for fine-tuning the manipulator 6 , locking 7 and rotation of the manipulator 8 .
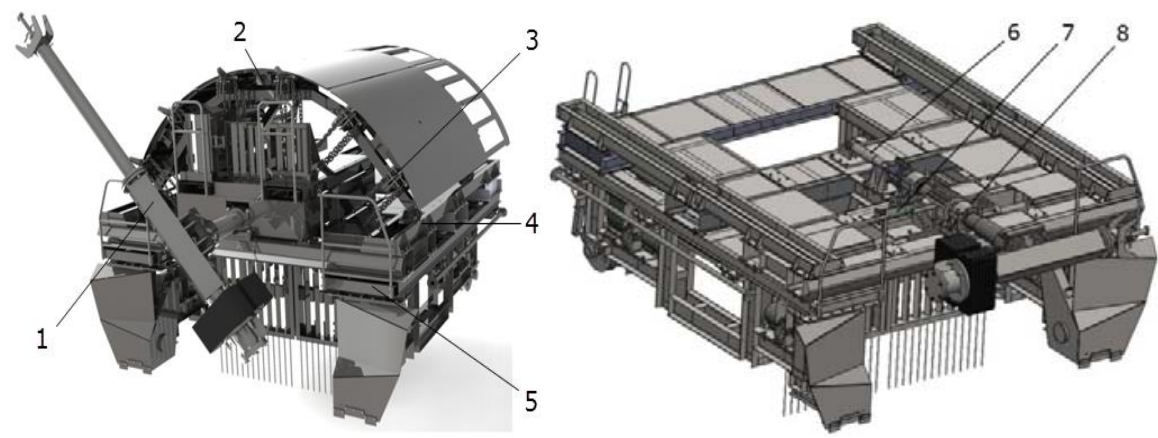

Fig. 1. Computer model of the tunnel erector made in the SOLIDWORKS program [29].

We will create solid-state assembly models for each device with positioner nodes adjacent to it and consider their operation. The manipulator moving device (Fig. 2) makes slight oscillatory movements. In the first approximation, we assume that the rod has the form of a point mass $M$ and moves translationally to a distance $L_{1}$.

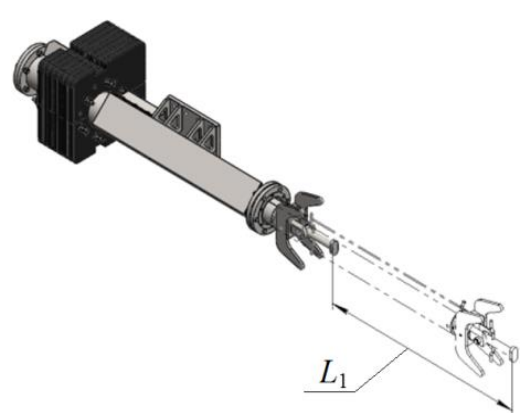

Fig. 2. Computer model of the device of the translational movement of the manipulator.

The manipulator rotation device (Fig. 3) is designed to ensure the installation of lining elements. It performs translational movement of the gear rack due to the displacement of the piston of the hydraulic cylinder to a distance $L_{2}$.

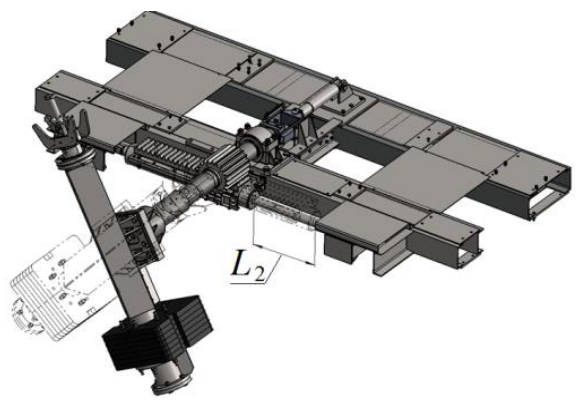

Fig. 3. A computer model of the rotation device of the manipulator. 
The translational displacement device (Fig. 4) is used to fine-tune the manipulator to a distance $L_{3}$, providing axial movement of the lining element for precise positioning during installation.

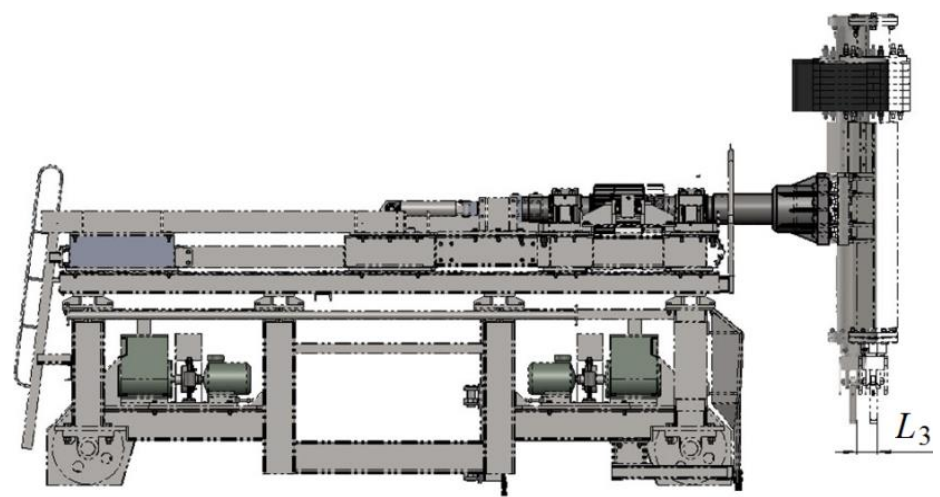

Fig. 4. Computer model of the device for translational movement of the fine-tune of the manipulator.

The device for translational movement of the visors (Fig. 5) ensures the extension of the visors to a distance $L_{4}$, protecting people from falling pieces of rock when laying lining elements in the lower part of the tunnel ring.

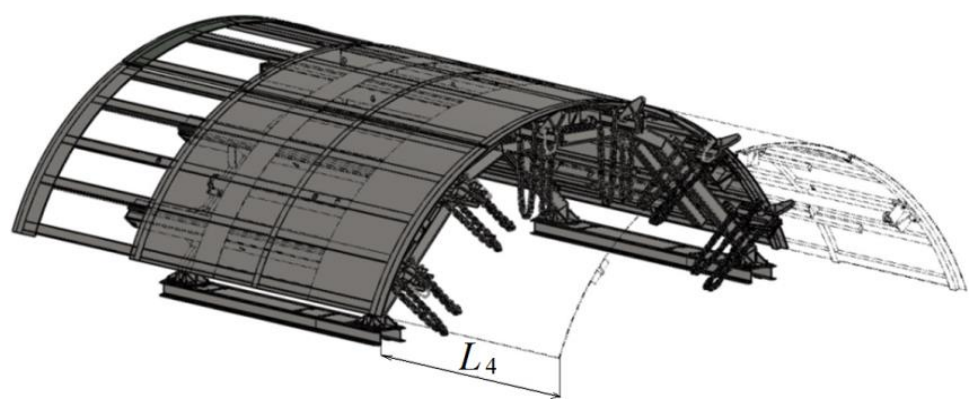

Fig. 5. Computer model of the translational movement of the visors.

The device for translational movement of the supporting beams (Fig. 6) ensures their extension to a distance $L_{5}$ and performs the function of supporting the elements of the tunnel lining (only ща the upper part of the tunnel ring) during their installation and shifting into the initial retracted state to allow further installation of the lining.

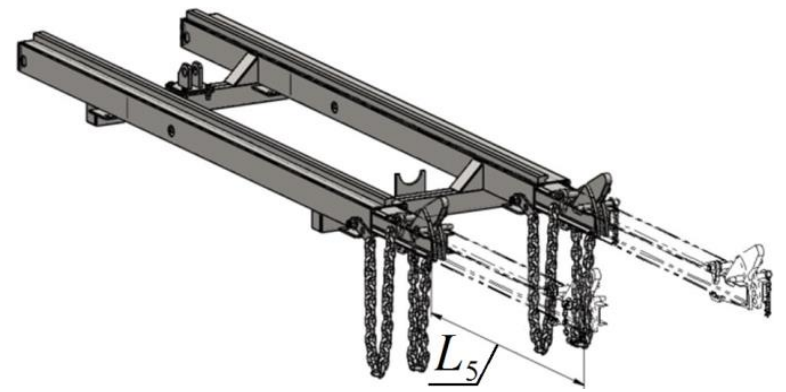

Fig. 6. Computer model of the translational movement of the supporting beams. 
The device for translational movement of the arch to a distance $L_{6}$ (Fig. 7) makes it possible to condense the seams between the elements from the working platforms, and return the arch to its original position to continue installation.

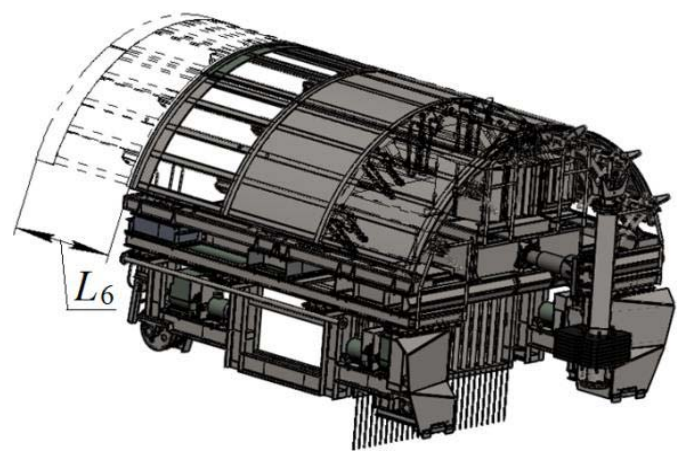

Fig. 7. Computer model of the translational movement of the arch.

The device for translational movement of service sites performs their extension to a distance $L_{7}$ (Fig. 8).

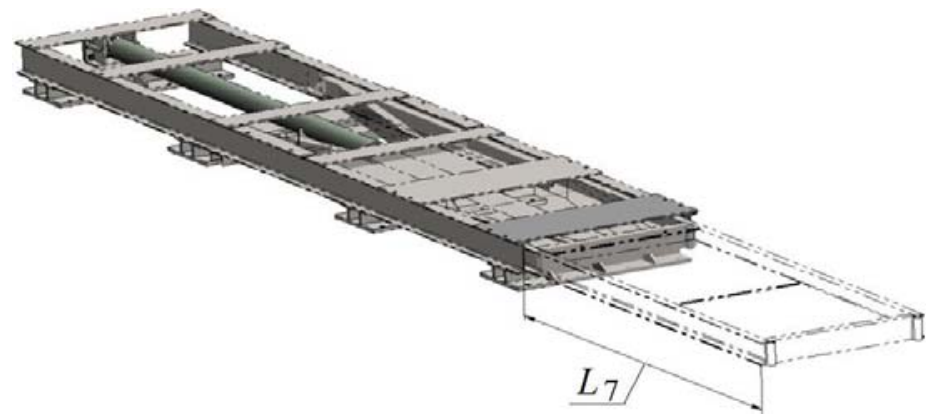

Fig. 8. A computer model of the device for translational movement of the service site.

An analysis of the erector devices listed above allows us to conclude that each is based on a drive in the form of a hydraulic cylinder (hereinafter the hydraulic cylinder), the piston of which moves to a predetermined distance $L$, so they all belong to the class of uniform (homogeneous) ones.

\section{Description of the structure of the metamodel}

For a detailed study of the functions of the above-listed devices, it is necessary to create their mechanical models [30]. In order not to simulate each of them, it is advisable, relying on the homogeneity of the objects, to develop a metamodel of a device with a hydraulic drive that allows the generation of all mechanical models of the mentioned devices.

It is based on a generalized mathematical model of all such devices [31], that is

$$
M \dot{x}=F_{r}(\dot{x})+F_{a}(\dot{x}, t),
$$

where $M$ is the point mass equivalent to the mass of all translationally moving parts of the device; $x$ is the generalized coordinate of the translational movement of mass $M$, $\ddot{x} \equiv \mathrm{d}^{2} x / \mathrm{d} t^{2} ; F_{r}$ is the generalized resistance force, $F_{a}$ is the generalized active force. 
We will set a task - to find such magnitude of force $F_{a}$ at which it would be possible to move the point mass $M$ to a distance $L$ in a minimum time. In other words, to ensure an increase in labor productivity when laying lining elements, fulfilling the conditions of strength and stiffness of the elements of the device.

In the method of a rational design of homogeneous erector devices, the created mechanical models of each of them are used. The models consist of three subsystems sequentially interacting with each other. Each subsystem solves its own problem:

1. Definition of the law of rational movement of the device using the kinematic model.

2. Formulation of an expression describing the control action on the basis of an analytical model of a hydraulic drive.

3. Clarification of the expression that describes the control action based on the device model using the MATLAB Simulink program [32].

We will consider each of the modeling subsystems.

\section{Kinematic model of devices}

To begin with, we study the analytical model of the motion of a point mass $M$, taking into account a given limit on acceleration $a^{*}$. Let the forces $F_{a}$ and $F_{r}$ be given and then the material point will move according to some law $x(t)$. During a translation motion of a point mass to a distance $L$, it is assumed that its acceleration and deceleration will occur in the same amount of time $0.5 T$, which should provide minimal acceleration in the areas where this takes place. Since the minimum value of the objective function of the optimization problem corresponds to the minimum possible rise time of the point mass, to determine the time $t$ to reach the given point $x$, it is necessary to introduce a function $t(x)$ inverse to the function $x(t)$. Then the rise time of the point mass to a height $L T=t(L)$.

It is assumed that at the beginning and at the end of the rise of the point mass there is no impact, that is, the speed $\dot{x}$ is zero.

From a mathematical point of view, the above optimization problem consists in determining the following ratio:

$$
\text { to find } x^{*}:\|x *\|=\min _{x \in \mathbf{X}}\|x\| \text {, }
$$

here the function inverse to $x(t)$ is $\|x\|=x^{\text {inv }}(L), \quad x^{\text {inv }}=t(x) ; \mathbb{X}$ is an admissible set of functions the derivative of which is symmetric with respect to $0.5 T\left(T=x^{\text {inv }}(L)\right)$, which satisfies the following conditions: $|\ddot{x}| \leq a^{*} ; x(0)=0 ; x(T)=L ; \dot{x}(0)=\dot{x}(T)=0$.

It is necessary to find such a value of the function $x(t)^{*}$, the norm of which, that is, the movement time corresponding to it, to the point $L$, will be minimal compared to the norm of the values of all other admissible functions, that is, the motion time according to the functions $x(t)^{*}$, will be minimal compared to the motion time that corresponds to the rest admissible functions $\mathbb{Y}$. To simplify the analysis of the optimization problem and reduce the number of values included in it, we introduce the following dimensionless variables: $\xi=x / L ; \tau=t \sqrt{a^{*} / L}$.

Then $\mathbb{Y}$ is an admissible set of dimensionless functions corresponding to $\mathbb{X}$, taking into account such conditions:

$$
\begin{gathered}
|\alpha| \leq 1 \\
\xi(0)=0
\end{gathered}
$$




$$
\begin{gathered}
\xi(k)=1 ; \\
\omega(0)=\omega(k)=0,
\end{gathered}
$$

where $\omega(\tau) \equiv \mathrm{d} \xi(\tau) / \mathrm{d} \tau \equiv \xi^{\prime}(\tau) ; \quad \alpha(\tau) \equiv \xi^{\prime \prime}(\tau) ; \quad k=T \sqrt{a^{*} / L}$

We choose five elementary functions for characterizing dimensionless acceleration values.

1. Cosine function. The expressions describing dimensionless accelerations and velocities, $\alpha(\tau)_{1}=\cos \left(\pi \tau / k_{1}\right) ; \omega(\tau)_{1}=\left(k_{1} / \pi\right) \sin \left(\pi \tau / k_{1}\right)$, correspond to conditions (1) and (4) if $0 \leq \tau \leq k_{1}$. After integration, we obtain the following expressions: $\xi(\tau)_{1}=-\left(k_{1}^{2} / \pi^{2}\right) \cdot \cos \left(\pi \tau / k_{1}\right)+C_{1}$. Taking into account condition (2), $C_{1}=k_{1}^{2} / \pi^{2}$, and condition $(3)-k_{1}=\pi / \sqrt{2}$.

2. U-shaped function $\alpha(\tau)_{2}=\left\{\begin{array}{cc}1, & \tau<0,5 k_{2} \\ -1, & \tau \geq 0,5 k_{2}\end{array}\right.$, где $0 \leq \tau \leq k_{2}$.

3. Linear function $\alpha(\tau)_{3}=1-\left(2 \tau / k_{3}\right)$, где $0 \leq \tau \leq k_{3}$.

4. Sinusoidal function $\alpha(\tau)_{4}=\sin \left(2 \pi \tau / k_{4}\right)$, где $0 \leq \tau \leq k_{4}$.

5. Sinusoidal cubic function $\alpha(\tau)_{5}=\sin ^{3}\left(2 \pi \tau / k_{5}\right)$, где $0 \leq \tau \leq k_{5}$.

Graphs of the considered functions are presented in Fig. 9

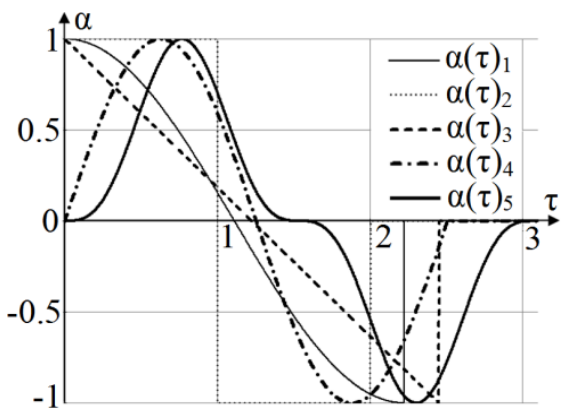

Fig. 9. Graphs of the functions of acceleration of the movement of the object.

Then the expressions for describing the values of dimensionless velocities $\omega$ will take the following form:

$$
\begin{aligned}
& \omega(\tau)_{2}=\left\{\begin{array}{cc}
\tau, & \tau<0,5 k_{2} \\
-\tau+k_{2}, & \tau \geq 0,5 k_{2}
\end{array}, \omega(\tau)_{3}=\tau-\frac{\tau^{2}}{k_{3}}, \omega(\tau)_{4}=\frac{k_{4}}{2 \pi}(1-\cos (2 \pi \tau / k 4)),\right. \\
& \omega(\tau)_{5}=\left(k_{5} / 6 \pi\right)\left(2-3 \cos \left(2 \pi \tau / k_{5}\right)+\cos ^{3}\left(2 \pi \tau / k_{5}\right)\right) .
\end{aligned}
$$

Then the dimensionless displacement values $\xi$

$$
\begin{aligned}
& \xi(\tau)_{2}=\left\{\begin{array}{cc}
\tau^{2} / 2, & \tau<0,5 k_{2} \\
-\tau^{2} / 2+k_{2} \tau-k_{2}^{2} / 4, & \tau \geq 0,5 k_{2}
\end{array} ; \quad \xi(\tau)_{3}=\left(\tau^{2} / 2-\tau^{3} / 3 k_{3}\right) ;\right. \\
& \xi(\tau)_{4}=k_{4} / 2 \pi\left(\tau-\sin \left(2 \pi \tau / k_{4}\right)\right) ; \quad \xi(\tau)_{5}=k_{5} / 6 \pi^{2}\left(2 \pi \tau / k_{5}-\sin \left(2 \pi \tau / k_{5}\right)-1 / 6 \sin ^{3}\left(2 \pi \tau / k_{5}\right)\right) .
\end{aligned}
$$


Dimensionless value of the end time of movement $k_{2}=2 ; k_{3}=\sqrt{6} ; \quad k_{4}=\sqrt{2 \pi}$; $k_{5}=\sqrt{3 \pi}$.

As it is seen in Fig. 9, the movement corresponding to each of the functions takes place at different times. This happens most quickly under the U-shaped law. The figures (Fig. 10 and Fig. 11) show graphs of the velocity and displacement functions, reflecting the five considered laws of block motion. From the condition of achieving a single dimensionless displacement value in a unit time, it follows that the areas of curved trapezoidal lines formed by each curve on the graph should be the same. In the picture of Fig. 11 we see that the selected options for moving the object slightly differ from each other, and the data of Fig. 10 show that the areas formed by the curves for each function corresponding to a unit displacement are the same, but the end time of the movement is different, respectively, for each function. For the convenience of comparing the values of these functions, we make such a change of variables: $\Omega(\tau)_{i}=k_{i} \omega\left(k_{i} \tau\right)_{i}$, where $i=1, \ldots, 5$ (Fig. 12).

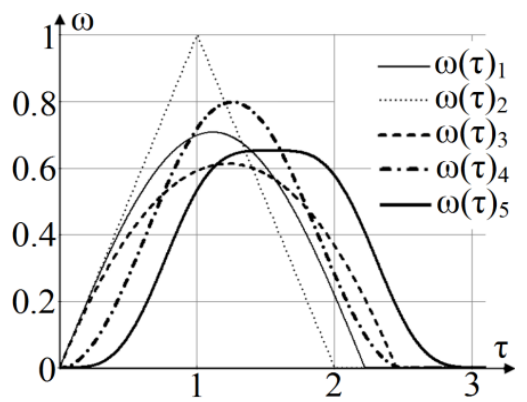

Fig. 10. Graphs of object velocity functions.

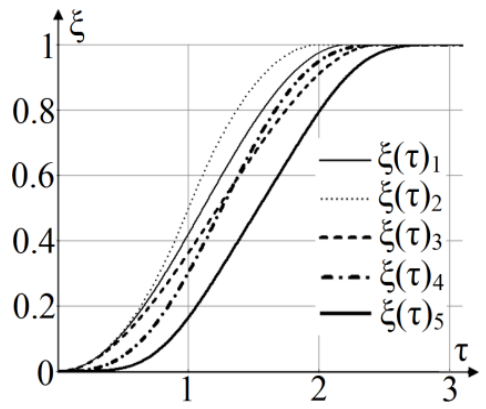

Fig. 11. Graphs of the functions of the movement of the object.

We take the velocity function corresponding to the U-shaped law of motion as the base function. We call the test function the derivative $\omega(\tau)$ of an arbitrary function $\xi(\tau)$ from an admissible set $\mathbb{Y}$. Two cases are possible. The curve of such function at zero has a slope (and hence acceleration) greater than the curve of the base function. Therefore, the selected function $\xi(\tau)$ cannot be a solution to the optimization problem. The second case is the case in which the slope of the curve at zero is less than the slope of the curve of the base function. At the beginning of the movement, the area of the curved trapezoid formed by the graph of the test function is less than the area formed by the graph of the base function. Therefore, there must necessarily be a point of intersection of the curves of the test function 
with the curves of the base one, when the slope of the first should be greater than the slope of the second one to balance the areas. It follows that an arbitrary function $\xi(\tau)$ cannot be a solution, since there is a time $\tau$ during which its second derivative will be longer than under the conditions of the U-shaped law of motion of the object.

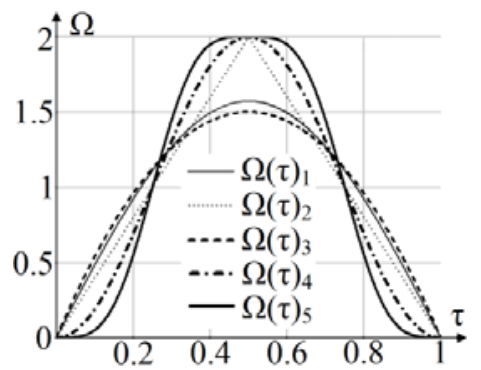

Fig. 12. A comparative analysis of the curves of functions of dimensionless velocity values.

We can conclude that the minimum time is achieved under the influence of a U-shaped law of movement of the object, which requires an instant change in the sign of acceleration. Under the influence of the smooth cosine law of movement, the time of the end of the movement of the object increases by $11 \%$. All other displacement options considered cause an even greater increase in time.

\section{Analytical model of hydraulic drive}

We will develop a mathematical model that allows us to establish the optimal law of controlling the movement of the spool of the hydraulic DCV when using the conditional concept of point mass $M$

Fig. 13 shows a schematic diagram of a hydraulic drive of erector devices, which consists of a constant pressure hydraulic pump $p_{0}$; hydraulic tank; 4-way hydraulic DCV, in which the stroke of the spool $u(t)$ depends on time; a double-acting hydraulic cylinder (hereinafter referred to as the hydraulic cylinder) and a material point with a mass $M$ affected by a resistance force $F_{r}$.

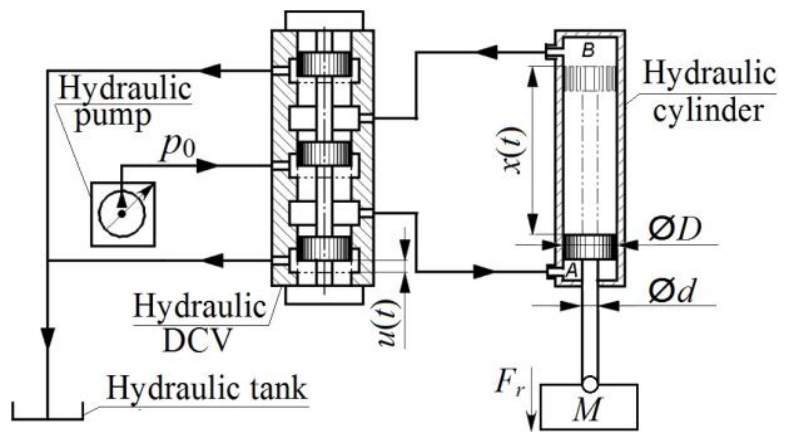

Fig. 13. Schematic diagram of the hydraulic drive of the DCV.

For the function of each channel of the spool, under the assumption that the inertia of the liquid is not taken into account, the following formula is valid, which reflects the flow rate of the liquid, the stroke of the spool and the pressure drop in its cavities, namely 


$$
q=\left\{\begin{array}{l}
C_{D} A \sqrt{2 / \rho|\Delta p|} \operatorname{sgn} \Delta p, \text { if } \mathrm{Re} \geq \mathrm{Re}_{c r}, \\
2 C_{D}^{2} / \operatorname{Re}_{c r} A D_{u} / v \rho \Delta p \text { if } \mathrm{Re}<\operatorname{Re}_{c r},
\end{array}\right.
$$

where $A=u A_{\max } / u_{\max } ; \operatorname{Re}=\left(q D_{u}\right) /(A v) ; D_{u}=\sqrt{4 A / \pi} ; q$ is liquid flow rate, $\mathrm{m}^{3} / \mathrm{s} ; \Delta p$ is differential pressure in the cavities of the hydraulic cylinder, $\mathrm{MPa} ; C_{D}$ is liquid flow coefficient in the spool; $A$ is instantaneous cross-sectional area of the hydraulic DCV, $\mathrm{m}^{2}$; $A_{\max }$ is the area of a fully open section, $\mathrm{m}^{2} ; u$ is spool movement, $\mathrm{m} ; u_{\max }$ is maximum possible movement of the spool, $\mathrm{m} ; \rho$ is liquid density, $\mathrm{kg} / \mathrm{m}^{3} ; \nu$ is kinematic viscosity of the liquid, $\mathrm{m}^{2} / \mathrm{s} ; D_{u}$ is hydraulic diameter of the holes of the hydraulic DCV, m; Re is Reynolds number; $\mathrm{Re}_{c r}$ is the critical value of the Reynolds number separating the laminar and turbulent regimes.

The law of motion of the piston in a double-acting hydraulic cylinder is described by this expression:

$$
M a=p_{0} A_{A}-p_{A} A_{A}-p_{B} A_{B}-F_{r},
$$

where $A_{A}=\pi\left(D^{2}-d^{2}\right) / 4 ; \quad A_{B}=\pi D^{2} / 4 ; \quad a=d^{2} x / d t^{2} ; \quad q_{A}=v A_{A} ; \quad q_{B}=v A_{B} ; \quad v=d x / d t ;$ $A_{A}$ is cross-sectional area of the rod cavity of the hydraulic cylinder, $\mathrm{m}^{2} ; A_{B}$ is the crosssectional area of the piston cavity of the hydraulic cylinder, $\mathrm{m}^{2} ; v$ - the speed of the piston movement of the hydraulic cylinder, $\mathrm{m} / \mathrm{s} ; a$ is acceleration of the movement of the piston of the hydraulic cylinder, $\mathrm{m} / \mathrm{s}^{2} ; q_{A}, q_{B}$ are flow rate of liquid passing through the corresponding cavity of the hydraulic cylinder, $\mathrm{m}^{3} / \mathrm{s} ; D$ is piston diameter, $\mathrm{m}$; $d$ is rod diameter, $\mathrm{m} ; M$ is total mass of the reinforced concrete block, piston and hydraulic rod, $\mathrm{kg}$; $F_{r}$ is resistance force, $\mathrm{N}$.

Then, in relation to the laminar and turbulent regimes of liquid movement in the hydraulic DCV at the given values $v(t)$ and $a(t)$, the movement of the spool $\left[u_{l}(t)\right.$ and $u_{t}(t)$ accordingly] should be carried out according to the law established using the developed mathematical model of the hydraulic drive, that is

$$
u_{l}(t)=\frac{u_{\max }}{A_{\max }}\left[\frac{v(t) v \rho \operatorname{Re}_{c r} \sqrt{\pi}\left(A_{A}^{2}+A_{B}^{2}\right)}{4 C_{D}^{2}\left(p_{0} A_{A}-F_{r}-M a(t)\right)}\right] ; u_{t}(t)=\frac{u_{\max }}{A_{\max }} v(t) \sqrt{\frac{\rho\left(A_{A}^{3}+A_{B}^{3}\right)}{p_{0} A_{A}-F_{r}-M a(t)}} .
$$

Minimum allowable rod cavity area $A_{A, \min }=\left(M a^{*}+F_{r}\right) / p_{0}$.

We investigate the dependence of the control law of the movement of the spool on the rod cavity area.

We denote that the relative excess of the rod cavity area from the minimum possible $b=A_{A} / A_{A, \min }$.

From formula (7) it follows that under the influence of the cosine law of motion of the block, the control of the movement of the spool as a function of dimensionless time values $\tau$ and $b$ takes the following form:

$$
f(\tau, b)=k_{2}(b) \sin (\pi \tau) / \sqrt{k_{1}(b)-\cos (\pi \tau)},
$$


here $k_{1}(b)=\left(p_{0} A_{A, \min } b-F_{r}\right) / M a^{*} ; k_{2}(b)=\left(u_{\max } T_{1} a^{*} / A_{\max } \pi\right) \sqrt{\rho\left(1+\lambda^{3}\right) A_{A, \min }{ }^{3} b^{3} / M a^{*}}$; $\lambda=A_{B} / A_{A} ; \tau=t / T_{1} ; T_{1}=\pi \sqrt{L / 2 a^{*}}$.

From expression (8) it follows that the movement of the object is possible only in the case when the applied pressure exceeds the loss of hydraulic resistance, i.e. $k_{1}(b)>1$.

As an example, we consider the rise of a reinforced concrete block to a height of 2 meters under the influence of the two considered laws of its motion (U-shaped and cosine) with minimum acceleration values for the entire period. The total mass of the reinforced concrete block, piston and rod of the hydraulic cylinder $M$ is 2 tons, the maximum acceleration is $a^{*}=2 \mathrm{~m} / \mathrm{s}^{2}$.

The figure (Figs. 14 and 15) shows the curves of the law of controlling the movement of the spool under the conditions of laminar and turbulent regimes of liquid flow obtained on the basis of the considered example.

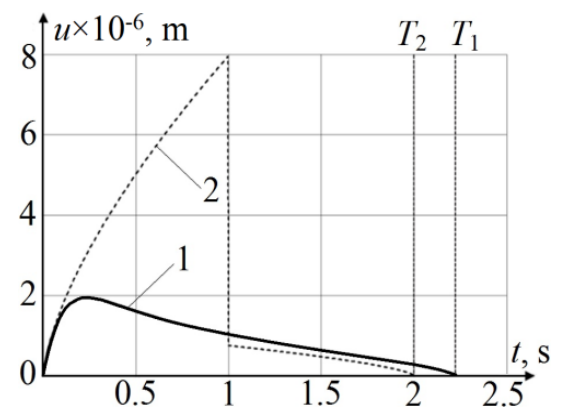

Fig. 14. Schedule of the law of control of the movement of the spool in the laminar regime: $1-$ cosine; 2 - U-shaped.

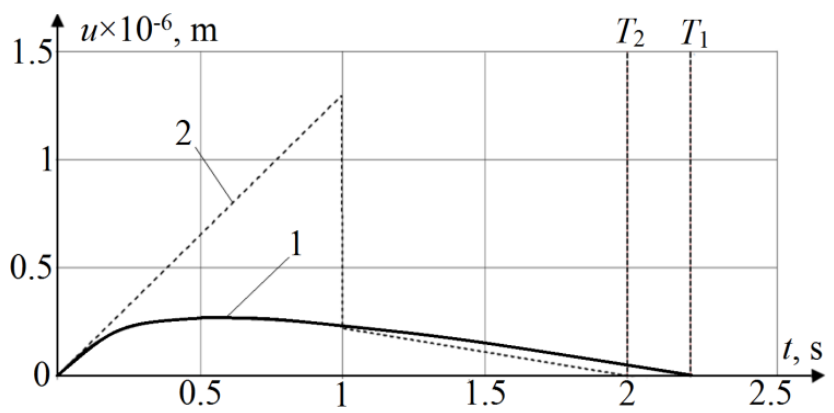

Fig. 15. Curves of the law of control of the movement of the spool in turbulent regime: 1 - cosine; $2-$ U-shaped.

From the figures it follows that under the influence of the U-shaped law of motion of the block, the time of its rise is reduced by $11 \%$, but it necessitates discontinuous control of the movement of the spool, which complicates the operation of the hydraulic drive control system, so it is advisable to use the cosine law.

Figures (Figs. 16 and 17) show the dependences of the Reynolds number, which characterizes the liquid flow in chamber $A$ of the hydraulic cylinder, on the time the unit was raised under laminar and turbulent flow conditions. 


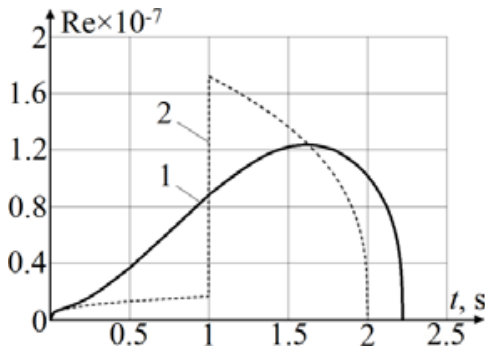

Fig. 16. Curves of the dependence of Reynolds number on time for laminar liquid flow: 1 - cosine law of motion of the block; 2 - U-shaped.

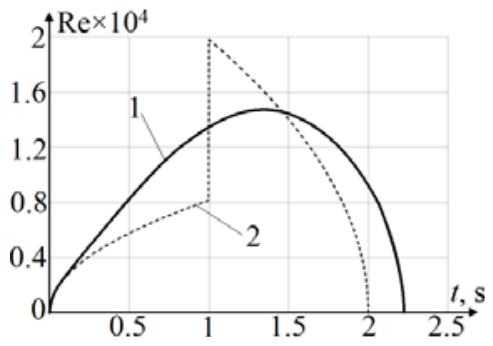

Fig. 17. Curves of the dependence of Reynolds number on time under turbulent liquid flow: 1 cosine law of motion of the block; 2 - U-shaped.

From the analysis of the graphs it follows that when opening the holes in the hydraulic $\mathrm{DCV}$, the Reynolds number significantly exceeds its own critical value, that is, there is a turbulent regime of liquid movement. Based on this, in the future we restrict ourselves to the action of only the cosine law of motion of the block.

The use of the mathematical model of the hydraulic drive in the erector device makes it possible to study the effect of several laws of movement of the point mass, to determine the law of control of the movement of the spool of the hydraulic DCV, in relation to the laminar and turbulent regimes of liquid flow. In this case, due to the excess of the Reynolds number of its own critical value, it is advisable to consider the law of controlling the movement of the spool, calculated on the turbulent regime of liquid movement. Under the influence of the U-shaped law of movement of the block, the time of its rise is reduced by $11 \%$ compared with the cosine one, but there is a need for discontinuous control of the movement of the spool, which complicates the operation of the entire hydraulic control system. You can specify the various control actions in the metamodel (Fig. 13) by simulating the device using the MATLAB Simulink program (SimHydraulics library).

\section{Conclusions}

The development of new methods for engineering perspective designs of mining machines is a relevant scientific problem. When considering the functions of the tunnel erector, the method of recurrent metamodeling, which is used in system analysis and in CASE technologies, is substantiated. The method provides that the metamodel of the entire family of such objects is associated with the family of models of nodes and machines. Various options for moving erector devices are analyzed and it is proved that its minimum time is observed under the influence of a U-shaped law. A mathematical model of the hydraulic drive of the erector devices is developed, with the help of which it was possible to consider several laws of the movement of the point mass, to determine the law of control of the 
movement of the spool of the hydraulic DCV in relation to the laminar and turbulent regimes of liquid flow. The metamodel of the erector device was created through the use of the algorithmic language MATLAB Simulink, and the use of the mathematical model of the hydraulic drives of this device has allowed us to study the control function and determine the law of motion with an error of $2.5 \%$.

Authors express gratitude to Yulii Dragomyretskyi, Director of the Design and Technological Institute for providing help and consultations during the work performance.

\section{References}

1. Taran, I.A., \& Klymenko, I.Yu. (2014). Innovative mathematical tools for benchmarking transmissions of transport vehicles. Naukovyi Visnyk Natsionalnoho Hirnychoho Universytetu, (3), 76-81.

2. Taran, I.A., \& Klymenko, I.Yu. (2014). Transfer ratio of double-split transmissions in case of planetary gear input. Naukovyi Visnyk Natsionalnoho Hirnychoho Universytetu, (6), 60-66.

3. Sładkowski, A., Utegenova, A., Kolga, A.D., Gavrishev, S.E., Stolpovskikh, I., \& Taran, I. (2019). Improving the efficiency of using dump trucks under conditions of career at open mining works. Naukovyi Visnyk Natsionalnoho Hirnychoho Universytetu, (2), 36-42. https://doi.org/10.29202/nvngu/2019-2/8

4. Zabolotnyi, K., \& Panchenko, O. (2019). Development of methods for optimizing the parameters of the body of a fixed jaw crusher. E3S Web of Conferences, (109). https://doi.org/10.1051/e3sconf/201910900121

5. Nadutyi, V.P., Sukharyov, V.V., \& Belyushyn, D.V. (2013). Determination of stress condition of vibrating feeder for ore drawing from the block under impact loads. Metallurgical and Mining Industry, 5(1), 24-26.

6. Zabolotny, K., \& Panchenko, E. (2010). Definition of rating loading in spires of multilayer winding of rubberrope cable. New Techniques and Technologies in Mining - Proceedings of the School of Underground Mining, 223-229. https://doi.org/10.1201/b11329-38

7. Zabolotnyi, K.S., Panchenko, O.V., Zhupiiev, O.L. \& Polushyna, M.V. (2018). Influence of parameters of a rubber-rope cable on the torsional stiffness of the body of the winding. Naukovyi Visnyk Natsionalnoho Hirnychoho Universytetu, (5), 54-63. https://doi.org/10.29202/nvngu/2018$\underline{5 / 11}$

8. Zabolotnyi, K., Panchenko, O., \& Zhupiiev, O. (2019). Development of the theory of laying a hoisting rope on the drum of a mining hoisting machine. E3S Web of Conferences, (109). https://doi.org/10.1051/e3sconf/201910900121

9. Moskalyova, T.V., \& Polushyna, M.V. (2015). Cross way of fastening steel ropes to a singledrum mine hoisting plant with the location of pulleys on the same axis. Naukovyi Visnyk Natsionalnoho Hirnychoho Universytetu, (3), 56-62.

10. Zabolotnyi, K., Panchenko O., Zhupiiev, O., Jamil Sami Haddad (2019). Justification of the algorithm for selecting the parameters of the elastic lining of the drums of mine hoisting machines. E3S Web of Conferences, (123). https://doi.org/10.1051/e3sconf/201912301021

11. Zabolotny, K., Zhupiev, O., \& Molodchenko, A. (2015). Analysis of current trends in development of mine hoists design engineering. New Developments in Mining Engineering, 175178. https://doi.org/10.1201/b19901-32

12. Mikhlin, Y. V., \& Zhupiev, A. L. (1997). An application of the ince algebraization to the stability of non-linear normal vibration modes. International Journal of Non-Linear Mechanics, 32(2), 393-409. https://doi.org/10.1016/s0020-7462(96)00047-9

13. Zabolotnyi, K.S., \& Zhupiiev, O.L. (2012) Study of deflected mode of mine winder split drums. Naukovyi Visnyk Natsionalnoho Hirnychoho Universytetu, (1), 82-87.

14. Zabolotny, K., Zinovyev, S., Zupiev, A., \& Panchenko, E. (2015). Rationale for the parameters equipment for rope dehydration of mining hoisting installations. New Developments in Mining 
Engineering 2015: Theoretical and Practical Solutions of Mineral Resources Mining, 275-281. https://doi.org/10.1201/b19901-49

15. Trokhymets, M., Maltseva, V., Vialushkin, Y., Antonchik, V., Moskalova, T., \& Polushyna, M. (2019). Method and equipment for the safe development of preparatory workings in the gasbearing coal seams. E3S Web Conferences, (109). https://doi.org/10.1051/e3sconf/201910900102

16. Kyrychenko, Y., Samusia, V., Kyrychenko, V., Romanyukov, A. (2013). Experimental investigation of aero-hydroelastic instability parameters of the deep-water hydrohoist pipeline. Middle-East Journal of Scientific Research, 18(4), 530-534.

17. Kyrychenko, E., Samusya, V., Kyrychenko, V., \& Antonenko, A. (2015). Thermodynamics of multiphase flows in relation to the calculation of deep-water hydraulic hoisting. New Developments in Mining Engineering 2015: Theoretical and Practical Solutions of Mineral Resources Mining, 305-311. https://doi.org/10.1201/b19901-54

18. Pivnyak, G., Samusia, V., Oksen, Y., \& Radiuk, M. (2015). Efficiency increase of heat pump technology for waste heat recovery in coal mines. New Developments in Mining Engineering 2015: Theoretical and Practical Solutions of Mineral Resources Mining, 1-4. https://doi.org/10.1201/b19901-2

19. Pivnyak, G., Samusia, V., Oksen, Y., \& Radiuk, M. (2014). Parameters optimization of heat pump units in mining enterprises. Progressive Technologies of Coal, Coalbed Methane, and Ores Mining, 19-24. https://doi.org/10.1201/b17547-5

20. Franchuk, V.P., Ziborov, K.A., Krivda, V.V., \& Fedoriachenko, S.O. (2018). Influence of thermophysical processes on the friction properties of wheel rail pair in the contact area. Naukovyi Visnyk Natsionalnoho Hirnychoho Universytetu, (2), 46-52. https://doi.org/10.29202/nvngu/2018$\underline{2 / 7}$

21. Ziborov, K., \& Fedoriachenko, S. (2014). The frictional work in pair wheel-rail in case of different structural scheme of mining rolling stock. Progressive Technologies of Coal, Coalbed Methane, and Ores Mining, 529-535. https://doi.org/10.1201/b17547-87

22. Ziborov, K., \& Fedoriachenko, S. (2015). Ziborov, K On influence of additional members' movability of mining vehicle on motion characteristics. New Developments in Mining Engineering 2015: Theoretical and Practical Solutions of Mineral Resources Mining, 237-241. https://doi.org/10.1201/b19901-42

23. Protsiv, V., Ziborov, K., \& Fedoriachenko, S. (2015). Test load envelope of semi - Premium O\&G pipe coupling with bayonet locks. New Developments in Mining Engineering 2015: Theoretical and Practical Solutions of Mineral Resources Mining, 261-264. https://doi.org/10.1201/b19901-46

24. HAO Wanjun, ZHANG Yanwei, CUI Guohua (2009). Research on the technical status of the segment erection system for the full shield tunneling machine. Mining \& Processing Equipment, (37), $1-5$.

25. Shi, H., Gong, G., Yang, H., \& Zhou, R. (2009). Position and Attitude Precision Analysis of Segment Erector of Shield Tunneling Machine. Lecture Notes in Computer Science, 355-363. https://doi.org/10.1007/978-3-642-10817-4 35

26. Yadong, G., Jun, C., Chao, W., Qingguo, Z., \& Shu, L. (2010). Research of the Segment Erector of Tunnel Boring Machine Based on Virtual Prototype. 2010 Second International Conference on Intelligent Human-Machine Systems and Cybernetics. https://doi.org/10.1109/ihmsc.2010.70

27. Lintao, W., Guofang, G., Hu, S., \& Dianqing, H. (2012). Positioning Precision and Impact Force Control of Segment Erector for Shield Tunneling Machine. 2012 Third International Conference on Digital Manufacturing \& Automation. https://doi.org/10.1109/icdma.2012.145

28. David Planchard. (2019). SOLIDWORKS 2019 Tutorial. SDC Publications, 640.

29. Li, G., Wang, B., Chen, Y. D., \& Wang, W. S. (2012). Research of Dynamics Simulation of a Six-DOF Segment Erector for Tunnel Boring Machine. Applied Mechanics and Materials, 249250, 291-294. https://doi.org/10.4028/www.scientific.net/amm.249-250.291

30. Reza N. Jazar. (2010). Theory of Applied Robotics. Springer Science + Business Media, LLC 2006, 894. 
31. Kolesnikov, K.S. (2005). Kurs teoreticheskoy mekhaniki. Moskva: Moskovskiy gosydarstvennyy tekhnicheskiy universitet im. Baumana, 736.

32. Devendra K. Chaturvedi (2010). Modeling and Simulation of Systems Using MATLAB and Simulink. CRC Press, 734. https://doi.org/10.1201/9781315218335 